\section{New Trends and Issues Proceedings on Humanities and Social Sciences}

Issue 1 (2017) 221-227

ISSN 2421-8030

www.prosoc.eu

Selected paper of 8th World Conference on Educational Sciences (WCES-2016), 4-8, February 2016, University of Alcala, Madrid, Spain

\title{
The development of indicators of good practice happy workplace organizations in Thailand
}

Siwaporn Poopana *, Department of Education, Faculty of Social Sciences and Humanities, Mahidol University, 10110, Thailand.

Athiwat Jiawiwatkul ${ }^{b}$, Department of Child and Family Development, Faculty of Social Sciences and Humanities, Mahidol University, 10110, Thailand.

\section{Suggested Citation:}

Poopan, S. \& Jiawiwatkul, A. (2017). The development of indicators of good practice happy workplace organizations in Thailand. New Trends and Issues Proceedings on Humanities and Social Sciences. [Online]. 01, pp 221-227. Available from: www.prosoc.eu

Selection and peer review under responsibility of Jesus Garcia Laborda, University of Alcala, Spain ${ }^{\circ} 2017$ SciencePark Research, Organization \& Counseling. All rights reserved.

\begin{abstract}
The purpose of this study was to develop indicators of good practice happy workplace organizations in Thailand. This study employed both documentary analysis and interviewing in order to generate indicators based on the stakeholders' perspectives. The findings revealed that indicators of good practice happy workplace organizations in Thailand consisted of three factors and seven indicators: input consisted of one indicator - leadership; process comprised of three indicators: organizational culture, work environment, and the operation of happy workplace organization; and outcome comprised of three indicators: individual outcomes; organizational outcomes; and the sustainability of happy workplace promotion. In terms of appropriateness, the majority of indicators of good practice happy workplace organizations in Thailand were evaluated in the highest level.
\end{abstract}

Keywords: Indicators, good practice, happy workplace organization, healthy organization.

* ADDRESS FOR CORRESPONDENCE: Siwaporn Poopan, Department of Education, Faculty of Social Sciences and Humanities, Mahidol University, 10110, Thailand.

E-mail address: greatsiwa@gmail.com / Tel.: +0-542-854-85-45 
Poopan, S. \& Jiawiwatkul, A. (2017). The development of indicators of good practice happy workplace organizations in Thailand. New Trends and Issues Proceedings on Humanities and Social Sciences. [Online]. 01, pp 221-227. Available from: www.prosoc.eu

\section{Introduction}

Nowadays, developing working and workplaces conditions as a healthy organization has become an important thing for organizations. Employees are a crucial resource in increasing productivity, competitiveness, and sustainability of the organizations. There are global agencies working to promote the concept of healthy organizations, for example, the World Health Organization (WHO) and European Network for Workplace Health Promotion (ENWHP).

The concept of healthy organization in Thailand was proposed by Health Promotion in Organizations Section, under Thai Health Promotion Foundation over the past 10 years in order to enhance the holistic health toward a high performance organization. The organization is one of the essential parts in driving the strategy forward in the changing of the health behaviors and to improve the well beings of the employees, their families, and people around them. If an organization is aware of health and well beings, now it is time to make use of the organization's potential to develop and support various communities to be sustainably well in terms of health (Vasantanarat, 2015). The consequences of operating by happy workplace are not only for the better health of Thai workers with better working efficiency but also for the development of societal stability, economic stability, and the reduction of the government's public health burdens.

There are many organizations implementing the happy workplace concept such as services industry and manufacturing industry. The Happy Workplace Awards for excellence are presented continually to organizations that have displayed outstanding performances in the area of happy workplace. Organizations need examples of good practices that they can use as guidelines (ENWHP, 2009). The concept of indicators of good practice happy workplace organizations in Thailand is a tool to evaluate the operation of happy workplace organization. Moreover, it is to find the good practice happy workplace organizations in Thailand, to exchange and share the experiences, and apply it in other organizations. Promoting happy workplace organizations, this study focused on the development of indicators of good practice happy workplace organizations. The indicators of good practice happy workplace organizations can be adapted to any workplace settings. The findings of this study would benefit the sustainable development of becoming healthy organization in Thailand.

\section{Objective of the study}

This study aimed to develop indicators of good practice happy workplace organizations in Thailand.

\section{Literature Review}

A concept of healthy organization in Thailand was proposed by Health Promotion in Organizations Section, under Thai Health Promotion Foundation over the past 10 years in order to enhance the holistic health toward a high performance organization. The happy workplace concept composed of eight components: good health (Happy Body); generosity (Happy Heart); peaceful or adherence to a religion (Happy Soul); relaxation (Happy Relax); educative or knowledge development (Happy Brain); debt-free or good financial status (Happy Money); good family (Happy Family); and good friend or contented society (Happy Society). Jiawiwatkul (2014) explained happy workplace concept as a Happy 8 Menu. Details are as follows:

- Happy Body - promoting healthy body and healthy mind through exercise and healthy diet in order to boost strong body and strong mind of the employees, which this results in efficient employees.

- Happy Heart - being kind and supportive to each other is to encourage kindness and generosity in the workplace to create good spirits and harmonize among employees.

- Happy Relax - being relaxed to things around is to create fun which can relax stressful working; this supports the cheerfulness and relationship among the employees. 
- Happy Brain - learning motivation, encourage employees to gain knowledge, skills and experiences in order to develop themselves continuously from variety learning sources, which lead them to be professional employees and have sustainable progress.

- Happy Money - efficiently saving and managing resources without any liabilities (debts) to enhance employees economize expenses as well as having reserve funds for emergency situations.

- Happy Soul - believing in religion and having morality to carry on daily life which helps to enhance the employee morality for mental happiness and peaceful mind.

- Happy Family - having a warm-hearted and stability within the families can help to enhance family's bond and relationship between employee's family and organization.

- Happy Society - a good society helps to support love, harmonization and generosity toward the surrounding community as well as providing assistant to nearby residences, since a good surrounding community would result in a happy organization.

The outcomes of healthy organization were divided into three categories: (1) individual outcomes such as higher levels of loyalty and organizational commitment; increased job satisfaction; decreased job stress; (2) organizational outcomes such as improved customer service; improved employee performance; decreased turnover and absenteeism; higher levels of productivity; organization reputation; and (3) societal outcomes such as national health-care costs; government programs (Health Canada, 2004; Kelloway \& Day, 2005).

\section{Research Methods}

This study employed qualitative research to develop indicators of good practice happy workplace organizations in Thailand. The research procedures were divided into three phases as follows:

Phase I was a documentary analysis of indicators of good practice happy workplace organizations, in which the data were collected from textbooks, articles, and published journals.

Phase II (qualitative study) was an informal interview in which the qualitative data were collected from 8 participants who have experienced a healthy organization. Maximum variation sampling was used to select the participants for this study. The criteria for selecting the participants are a group of happy workplace experienced: (1) happy workplace practitioners in organizations; (2) happy workplace practitioners in the regionals; (3) happy workplace researchers; and (4) scholars who have experienced healthy organization. The data were collected using an interview protocol. The qualitative data were analyzed by employing textual analysis.

Phase III (a synthesis of indicators of good practice happy workplace organizations), in this phase of study, the findings from phase I and phase II were taken into consideration in order to investigate the indicators of good practice happy workplace organizations in terms of appropriateness. The research instrument was questionnaire. Descriptive analysis was analyzed by using a computer program.

\section{Research Results}

\subsection{Indicators of good practice happy workplace organization}

From a documentary analysis, the findings revealed that indicators of good practice happy workplace organization in Thailand consisted of three major factors - input; process; and outcome.

From the interviews, three themes emerged about indicators of good practice happy workplace organizations: input; process; and outcome.

Theme 1: Input of happy workplace organization 
Many significant experiences participants focused on input of happy workplace organization. These included (1) happy workplace policy formation and (2) organizing happy workplace committee. The participants' experience illustrates the happy workplace policy formation:

"The administrators place a high priority on developing healthy organization (...) the administrators with explicit visionary in developing employees in the organization are willing to support all employees work and activities."

"Apart from a distinction in determining the organizational policies, visions, and mission to produce, a need to emphasize on the employees is also important as part of the organization's policy to create a happy workplace."

In terms of organizing happy workplace committee, the participants' experience illustrate the happy workplace policy committee as follows:

"A good practice happy workplace organization need to organize the happy workplace committee, provide a detailed workflow and corporate responsibility in project."

Theme 2: Processes of happy workplace organization

The participants reflected the processes of happy workplace organization such as staff involvement in happy workplace activities; utilizing happy workplace tools; monitoring and evaluation of the operation on happy workplace as follows:

"Communicating with employees to develop employee involvement toward healthy organization."

"Utilizing the happy workplace tools for supporting the operation of happy workplace such as a measurement of happiness, both individual happiness and organizational happiness reflect the empirical results"

"The organization has a good evaluation system such as upstream evaluation; midstream evaluation; and downstream evaluation by using happy workplace tools for example happinometer; happy index; and ROI (...) including the use of evaluation for enhancing the operation of happy workplace."

Theme 3: Outcomes of happy workplace organization

A third theme reflected the outcomes of happy workplace organization including individual outcomes; organizational outcomes; and the sustainability of happy workplace promotion. The participants' experience illustrate the outcomes of happy workplace organization as follows:

"People in the organization are eager to work with creative mind ...as well as positive thinking and optimistic world view."

"An operation of happy workplace project caused the consequences such as decreased turnover, compare the latest turnover rate."

"Employees are loyal to their organizations."

"Have a good knowledge and of happy workplace, understand the procedure of healthy workplace promotion, and become a mentor for other organizations."

Based on a documentary analysis and the interviews, the findings revealed that the indicators of good practice happy workplace organizations in Thailand consisted of three factors and seven indicators is shown in Figure 1. The first factor was input which was composed of one indicator: leadership. The second factor was process which was comprised of three indicators as follows: organizational culture, work environment, and the operation of happy workplace organization. The third factor was outcome which was comprised of three indicators namely individual outcomes, organizational outcomes, and the sustainability of happy workplace promotion. 


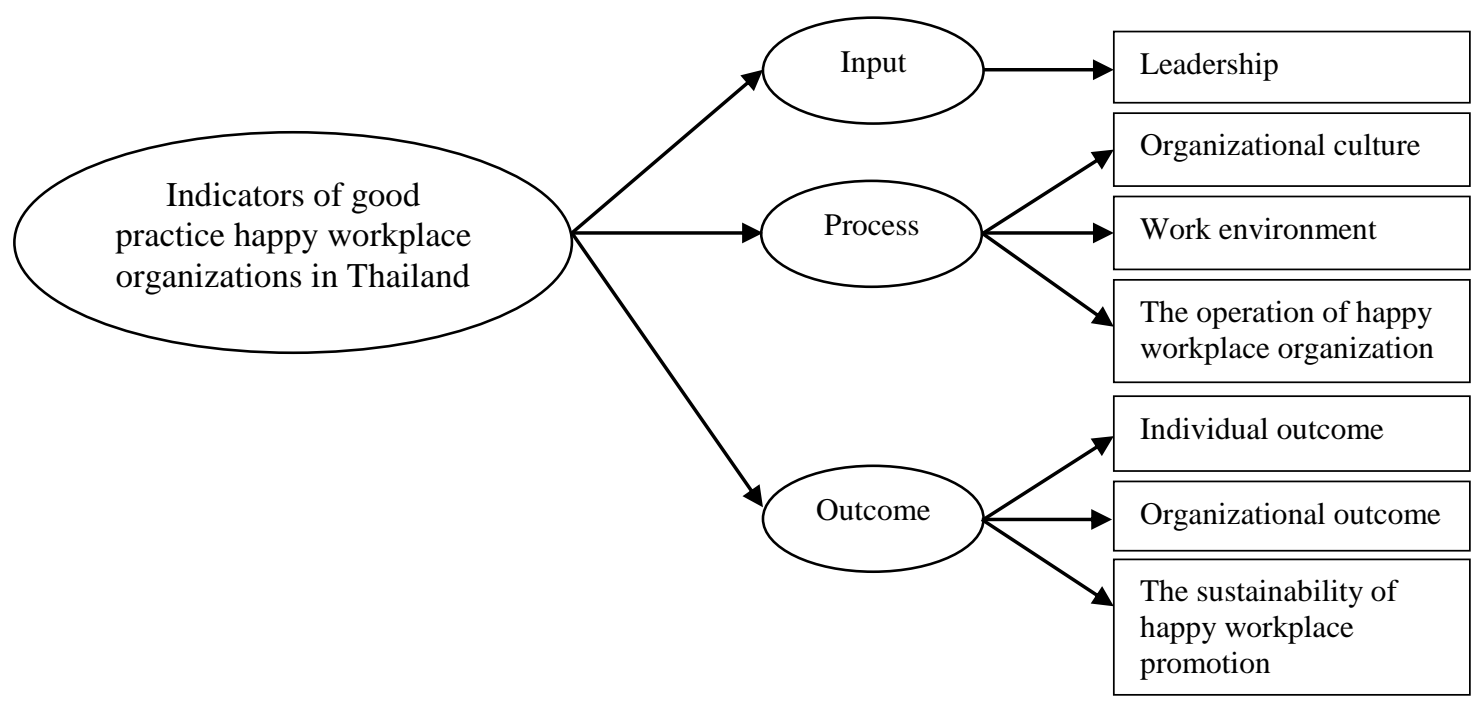

Figure 1. The indicators of good practice happy workplace organizations in Thailand

\subsection{The appropriateness of indicators of good practice happy workplace organization}

The indicators were evaluated with three factors; (1) input consisted of one indicator - leadership; (2) process comprised of three indicators; organizational culture, work environment, and the operation of happy workplace organization; and (3) outcome comprised of three indicators: individual outcomes; organizational outcomes; and the sustainability of happy workplace promotion, as shown in Table 1. The descriptive statistics included mean $(M)$ and standard deviation (SD). The researcher had assigned a criteria for understanding the appropriateness into five levels; lowest level represented a mean of $1.00-1.80$, low level represented a mean of $1.81-2.60$, moderate level represented a mean $2.61-3.40$, high level represented a mean of $3.41-4.20$, and the highest level represented a mean $4.21-5.00$.

All factors were evaluated in the highest level. The highest appropriateness was assessed with the input $(M=4.72)$, followed by process $(M=4.67)$ and outcome $(M=4.37)$. The evaluation also suggested that among seven indicators, the range of the appropriateness was between $4.20-4.72$. Six indicators were evaluated in the highest level. However, there were two indicators were evaluated at high level; individual outcomes $(M=4.20)$ and organizational outcomes $(M=4.20)$.

Table 1. The appropriateness of indicators of good practice happy workplace organizations in Thailand

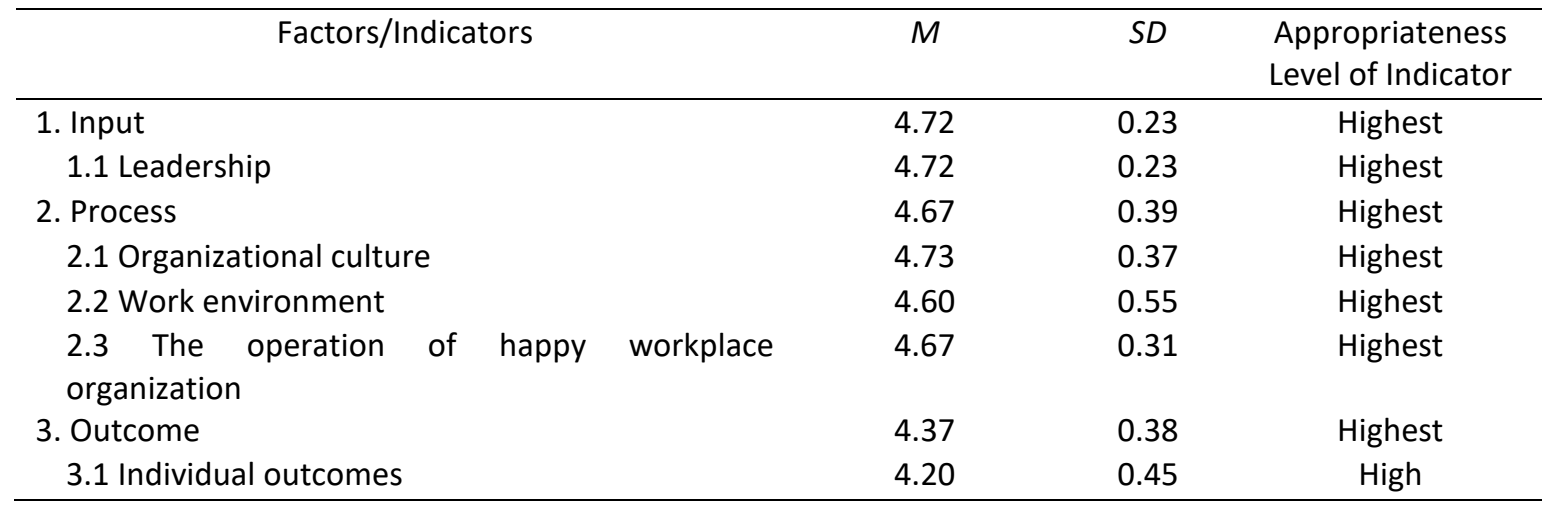


Poopan, S. \& Jiawiwatkul, A. (2017). The development of indicators of good practice happy workplace organizations in Thailand. New Trends and Issues Proceedings on Humanities and Social Sciences. [Online]. 01, pp 221-227. Available from: www.prosoc.eu

\begin{tabular}{llllc}
3.2 Organizational outcomes & & 4.20 & 0.45 & High \\
3.3 The sustainability of happy workplace & 4.70 & 0.45 & Highest \\
promotion & & & \\
\hline
\end{tabular}

\section{Discussions and Recommendations}

The findings have confirmed that the indicators of good practice happy workplace organization consisted of three factors and seven indicators; (1) input consisting of leadership; (2) process consisting of organizational culture, work environment, and the operation of happy workplace organization; and (3) outcome consisting of individual outcomes; organizational outcomes; and the sustainability of happy workplace promotion. In terms of appropriateness, the majority of indicators of good practice happy workplace organization in Thailand were evaluated in the highest level while two indicators were evaluated at high level. Since the researcher employed both documentary analysis and the interviews in order to generate indicators based on the stakeholders' perspectives, it would be interesting to validate the indicators of good practice happy workplace organization in Thailand by employing confirmatory factor analysis (CFA) which the researcher can explain the indicators in terms of factor loading and factor scale.

\section{Acknowledgements}

This research is part of the "The Development of Academic Mechanisms for Healthy Workplace Promotion" project. Special thanks to Health Promotion in Organizations Section, Thai Health Promotion Foundation for the financial support. Moreover, I would like to thank the Faculty of Social Sciences and Humanities, Mahidol University for the scholarship support for presentation in abroad.

\section{References}

Burton, J. (2010). WHO healthy workplace framework and model: Background and supporting literature and practices. Submitted to Evelyn Kortum. (WHO Headquarters, Geneva, Switzerland February 2010).

Corbett, D. (2004). Excellence in Canada: Healthy organizations-achieve results by acting responsibly. Journal of Business Ethic. 55, 125-133.

Creswell, J. W. (2013). Qualitative inquiry and research design: Choosing among five approaches. 3rd ed.. Thousand Oaks, CA: Sage.

ENWHP. (2009). European network for workplace health promotion. Essen: Woeste Druck.

Jiawiwatkul, A. (2010). 7Cs: Success factors in area-based happy workplace promotion. In Jiawiwatkul, A. (Eds.), Shortcut for building happy workplace: Case study from 6 provincial partners (pp. 17-21). Bangkok: Happy Workplace Private Sector Plan, Thai Health Promotion Foundation. (Thai manuscript)

Jiawiwatkul, U. (2014). Happy 8 menu. Bangkok: P.A. Living. (Thai manuscript)

Kelloway, E. K. and Day, A. L. (2005). Building healthy workplaces: What we know so far. Canadian Journal of Behavioural Science, 37(4): 223 - 235.

Klaiyam, K. \& Jiawiwatkul, A. (2012). Gross workplace happiness. Retrieved from http://www.happyworkplace.com/userfiles/file/Article09 en.pdf

Miles, M. B., \& Huberman, A. M. (1994). Qualitative data analysis. 2 nd ed. Thousand Oaks, CA: Sage.

Muylaert, K., Beeck, R., \& Broek, K. (2007). Company health check: An instrument to promote health at the workplace. Review Paper and Catalogue Quality of Criteria. 
Poopan, S. \& Klakhang, S. (2014). The happy workplace policy development. In Jiawiwatkul, A. (Eds.), Concepts of happy workplace Series III: Driving the happy workplace (pp. 42-67). Bangkok: P.A. Living. (Thai manuscript)

Stake, R. E. (2010). Qualitative research: Studying how things work. NY: Guilford Press.

Thakur, J.S. Bains, P., Kar, S.S., Wadhwa, S., Moirangthem, P., Kumar, R., Wadwalker, S. \& Sharma, Y. (2012). Integrated healthy workplace model - An experience from North Indian industry. Indian Journal of Occupational \& Environmental Medicine, 16(3), 108-113.

Vasantanarat, C. (2015). Well-being and workers. Retrieved from http://en.thaihealth.or.th/NEWS/67/Wellbeing\%20and\%20Workers/

Visaetsilapanonta, P. \& Ramrong, T. (2014). Good practice healthy organization. In Jiawiwatkul, A. (Eds.), Concepts of happy workplace Series III: Driving the happy workplace (pp. 1-41). Bangkok: P.A. Living. (Thai manuscript)

Yamato, S. (2011). Effect of happy workplace program: A case study of 2 firms in Thailand. (Unpublished Thesis). Chulalongkorn University, Thailand. 